\title{
Intensive care unit capacity and mortality in older adults: a three nations retrospective observational cohort study
}

Ran Abuhasira ${ }^{1,2+} \oplus$, Matthew Anstey ${ }^{3,4,5+}$, Victor Novack ${ }^{1,2}$, Somnath Bose ${ }^{6,7}$, Daniel Talmor ${ }^{6}$ and Lior Fuchs L $^{2,8^{*}}$

\begin{abstract}
Background: Intensive care unit (ICU) admissions among older adults are expected to increase, while the benefit remains uncertain. The availability of ICU beds varies between hospitals and between countries and is an important factor in the decision to admit older adults in the ICU. We aimed to assess if a non-restrictive approach to ICU older adults admission is associated with a corresponding change in survival.
\end{abstract}

Methods: Retrospective cohort study that included patients $\geq 80$ years who were admitted to each of the three participating hospitals in Australia, Israel, and the United States (USA), between the years 2006-2015, each with distinct ICU capacities and admission criteria. The primary outcomes were in-hospital mortality and all-cause mortality at 6, 12, 18 , and 24 months following index hospitalization.

Results: The cohort included 62,866 patients with a mean age of $85.9 \pm 4.6$ years and $58.8 \%$ were women. The ICU admission rates were $22.5 \%, 2.6 \%$ and $2.3 \%$ in USA, Australia, and Israel, respectively. We constructed a model for ICU admissions based on the USA cohort (highest availability of ICU beds) and then calculated the expected probabilities for the Israeli and Australian cohorts. For the patients in the highest quintile of the admission model, actual ICU admission rates were 67.6\% in USA, 22.1\% in Australia and 6.0\% in Israel. Of these, in-hospital death rates were 52.3\% in Israel, $29.8 \%$ in Australia, and $22.1 \%$ in USA. Two years after hospital discharge, the survival rates in the USA and Australia were $53 \%$, while in Israel $48 \%$.

Conclusion: ICU admission of adults $\geq 80$ years is associated with increased in-hospital survival compared to ward admission, but survival rates 2 years later are similar.

Keywords: Intensive care unit, Aged, Elderly, Hospital mortality

\section{Background}

The number of older adults requiring intensive care unit (ICU) admission is increasing and is associated with significant costs and resource utilization $[1,2]$. This trend is expected to increase given the ageing global population [3]. Age is a significant independent risk factor for in-ICU mortality, but uncertainty remains whether ICU

\footnotetext{
*Correspondence: liorfuchs@gmail.com

${ }^{\dagger}$ Ran Abuhasira and Matthew Anstey have equal contribution

${ }^{2}$ Faculty of Health Sciences, Ben-Gurion University of the Negev, Beer Sheva, Israel

Full list of author information is available at the end of the article
}

admission in this population confers any short-term, or long-term benefit to patients [4-7].

This raises the question: should age be included in the decision-making processes for admission to intensive care, especially when there are capacity restraints [7]? A national French study showed that emergency and intensive care unit physicians were highly reluctant to consider intensive care unit admission of patients aged 80 years, despite the presence of criteria indicating that intensive care unit admission was certainly or possibly appropriate [8].

\section{Springer Open}

(c) The Author(s) 2022. Open Access This article is licensed under a Creative Commons Attribution 4.0 International License, which permits use, sharing, adaptation, distribution and reproduction in any medium or format, as long as you give appropriate credit to the original author(s) and the source, provide a link to the Creative Commons licence, and indicate if changes were made. The images or other third party material in this article are included in the article's Creative Commons licence, unless indicated otherwise in a credit line to the material. If material is not included in the article's Creative Commons licence and your intended use is not permitted by statutory regulation or exceeds the permitted use, you will need to obtain permission directly from the copyright holder. To view a copy of this licence, visit http://creativecommons.org/licenses/by/4.0/. 
Lower ratio of ICU to non-ICU beds and association to higher mortality of older adults were described previously $[9,10]$. Increasing ICU capacity led to an increase in admissions of older adults, but without improvement in 1-year mortality rates in a study from Israel [6].

Nonetheless, there may be some benefit for older adults to be admitted to ICUs. One report found that up to $50 \%$ of patients discharged from the hospital were still alive at 2 years [11]. Another study concluded that despite the fact that older adults have more intensive care unit refusals than younger patients and have higher mortality when admitted, the mortality reduction for older adults that are admitted to the ICU is greater than younger patients [12].

An alternative to a randomized control study is to make use of the existing differences between countries and health systems in the availability of ICU beds. The number of older adults treated in ICUs differs between countries, approximately in proportion to the available ICU beds [13]. This provides a setting for a natural experiment that can be utilized to evaluate the potential benefits or harms associated with increased ICU utilization in this sub-population. Results of such a study can facilitate discussion with patients and families based on accurate data about the true value of opting for management in intensive care units across different countries.

We aimed to assess if a non-restrictive approach to ICU admissions among eligible older adults improves inhospital and long-term survival. We hypothesized that this approach would not increase long-term survival.

\section{Methods}

\section{Study design, population, and outcomes}

This is a retrospective cohort study that included patients aged 80 years or older who were admitted to each of the three participating hospitals-Soroka University Medical Center (SUMC) in Israel, Sir Charles Gairdner Hospital (SCGH) in Australia, and Beth Israel Deaconess Medical Center (BIDMC) in Boston, United States of America (USA). The three hospitals are all major tertiary level, academic, referral hospitals in their cities. Admissions in Israel and Australia were analyzed between the years 2006 and 2015 and in Boston between the years 20092015. These patients were sub-grouped into those who were admitted to an ICU and those who were admitted to a general ward. Only the first admission of every patient within the defined period of the study was analyzed. Within the index admission, only the first department and the first ICU admission were included in the analysis. Readmissions were considered as admissions occurring 6 months or less after discharge.

Exclusion criteria included: hospitalization for less than $24 \mathrm{~h}$; admission for psychiatric conditions; admission for acute coronary syndrome as a primary diagnosis; advanced directives of CMO (comfort measures only) on day one of ICU admission; cardiac surgery patients (as elective patients) and absence of laboratory data on the admission.

The primary outcomes were in-hospital mortality and all-cause mortality at $6,12,18$, and 24 months. Secondary outcomes were incidence of all ICU admissions among this age group in each medical center; ICU and ward mortality rates; ICU and hospital length of stay; and home discharge rates.

\section{Clinical definitions and data sources}

We used the Charlson's comorbidity index to quantify the severity of comorbidities and identified them by ICD-9 and ICD-10 codes during the hospitalizations and by data obtained from community clinics [14]. The Laboratory-Based Acute Physiology Score (LAPS) is a validated score that predicts in-hospital mortality in various primary diagnoses based on laboratory data only [15]. The score ranges between a minimum of 0 and a theoretical maximum of 256. For the LAPS calculation, we included the first lab results of every test in the first admission.

The Australian data were linked using data from the hospital admission dataset, the state mortality dataset (with follow-up of 2 years after discharge), and the pathology provider.

Due to technical difficulties, we could not obtain longterm mortality data of the BIDMC cohort. Thus, for comparison on long-term mortality rates, we used the data of the Israeli and Australian cohorts and compared it to the 'Medical Information Mart for Intensive Care' (MIMICIII) database between 2009 and 2012 [16]. This comparison is valid since MIMIC-III data are derived only from BIDMC, taken from years included in our study, and from the same ICUs, and therefore including an unbiased part of the same cohort.

\section{ICU capacities and admission policies}

In all countries, ICU beds were calculated only if they are a part of a designated ICU unit with a team that is specialized in intensive care.

At SUMC, Beer Sheva, Israel, there are 827 adult beds and 24 ICU beds, respectively (ICU beds are $2.9 \%$ of all hospital beds, a ratio of 34:1). There are 16 general ICU beds and 8 medical ICU beds. This hospital is characterized by a highly restrictive triage policy. The admissions are at the discretion of the admitting intensive care specialist. Patients who are believed to have an irreversible clinical condition are mechanically ventilated in the internal medicine departments in most cases. ICU patients typically present with an acute need for mechanical ventilation or hemodynamic instability. SUMC is the only tertiary medical center in the city and serves as the 
tertiary center for a population of approximately 1 million people. It is the only hospital in the region of Southern Israel that provides cardiothoracic surgery, vascular surgery, and neurosurgery services.

At SCGH, Perth, Western Australia (WA), there are 600 adult and 23 adult ICU beds, respectively (ICU beds are $3.8 \%$ of all hospital beds, a ratio of $25: 1$ ). All the ICU beds are mixed with no differentiation between types of ICU. This ratio leads to a more restrictive ICU admission policy with ICU admission triaged on the basis of acuity, comorbidities, and prognosis. The admissions are at the discretion of the admitting intensive care specialist. No mechanical ventilation occurs outside of the single designated ICU areas in the hospital. There are 3 major referral ICUs in Perth, a city of 2 million people. SCGH is the only hospital in the state of WA providing neuro-interventional radiology services and liver transplantation. It also includes cardiothoracic surgery, vascular surgery, and neurosurgery services.

At BIDMC, Boston, USA, there are 621 adult and 77 ICU beds, respectively (ICU beds are 13\% of all hospital beds, a ratio of 8:1). The breakup of ICU beds at BIDMC: 28 medical, 8 neurology, 18 trauma and surgical, 15 cardiovascular surgical, and 8 cardiac. This hospital is characterized by a liberal ICU admission policy wherein no broad-based exclusion criteria are implemented. When one of the ICUs is full (surgical-ICU, trauma-ICU, three medical-ICUs, cardiovascular-ICU, and cardiac-ICU), the patients are admitted in another suitable ICU or to the post-anesthesia care unit (PACU) as a "boarder". This facilitates a policy of no refusal of ICU care for patients that are evaluated as requiring it. BIDMC is a tertiary level academic medical center serving Eastern Massachusetts and serves a catchment area of $\sim 1$ million people. Within the city of Boston (population of 4.5 million people) there are 5 other tertiary level academic medical centers and quite a few satellite hospitals within close proximity. Tertiary level centers in Boston provide similar services with few exceptions.

At SUMC and SCGH, ICU admissions are at the discretion of the admitting intensive care specialist and are "closed units" for the purposes of management, although teams are welcome to visit and provide their expertise and share in the care of the patient. In all centers, the medical insurance of the patient does not affect the ICU admission policy. Lawsuits are uncommon in intensive care in all countries.

\section{Statistical analysis}

Demographics and baseline clinical characteristics are presented as mean (SD) or median (IQR) as appropriate. When appropriate, we made univariate comparisons using $\mathrm{X}^{2}$-test for categorical variables and using one-way ANOVA or Kruskal-Wallis test for quantitative variables.

We used multivariable logistic regression to characterize the factors determining ICU admission in the American cohort. Variables with a significance of $<0.1$ in the univariate analysis were inserted to the multivariable model. This model has a c-statistic of 0.8 demonstrating good discrimination. With the results of the logistic regression, we calculated a score for all patients, based on sex, age, Charlson score, LAPS, and primary admission diagnosis. The purpose of the score was to predict the probability of Israeli and Australian patients to be admitted to the ICU, based on the American model. All patients were divided into quintiles of probability to be admitted to the ICU. In every quintile, we compared the actual admission allocation and the in-hospital mortality rates between the different countries, both in the wards and in the ICUs.

Patients in the 5th quintile in the Israeli and Australian cohort, i.e., patients with the highest probability to be admitted to the ICU, according to the American model, were compared according to the primary and secondary outcomes. Mortality data were linked with the state death database in Australia, obtained from the MIMIC database for the USA, and from the state database in Israel. We calculated survival according to the KaplanMeier method with log-rank test.

A $p$ value of 0.05 or less (two-sided) was considered statistically significant. Statistical analyses were performed with Stata, version 13.0 (StataCorp, Texas, USA) and SPSS, version 25 (IBM Corp).

\section{Results}

\section{Study population}

The study cohort included 62,866 patients aged 80 years or older who were admitted to any participating center during the study period. Israel, USA, and Australia comprised $17.2 \%, 57.1 \%$, and $25.7 \%$ of the cohort, respectively.

The mean age was $85.93 \pm 4.62$ years, and $58.8 \%$ were women. The ICU admission rates differed substantially between Israel and Australia, with rates of $2.3 \%$ and $2.6 \%$, respectively, and USA, with $22.5 \%$. Duration of hospitalization was the longest in Australia, whereas ICU admission time was similar across centers (Table 1). Discharge destination also differed significantly between the centers, with $91.6 \%$ of the Israeli cohort discharged to their homes, compared to $42.9 \%$ and $52.0 \%$ in the American and Australian cohorts, respectively. In the American cohort, $35.1 \%$ were discharged to a long-term care/nursing home, compared to $9.2 \%$ in Australia. $19.7 \%$ of the Australian cohort were transferred to other hospitals.

Re-admission rate was highest among the American cohort (Table 1). The characteristics of patients with the 
Table 1 Characteristics of the patients at first admission

\begin{tabular}{|c|c|c|c|c|c|}
\hline Variable & Israel $(n=10,847)$ & USA $(n=35,875)$ & Australia $(n=16,144)$ & All $(N=62,866)$ & $p$ value \\
\hline \multicolumn{6}{|l|}{ Age (years) } \\
\hline $\begin{array}{l}\text { Mean } \pm \text { SD } \\
\text { Median (IQR) }\end{array}$ & $\begin{array}{l}85.36 \pm 4.42 \\
84(82-88)\end{array}$ & $\begin{array}{l}86.19 \pm 4.67 \\
85(82-89)\end{array}$ & $\begin{array}{l}85.75 \pm 4.6 \\
85(82-89)\end{array}$ & $\begin{array}{l}85.93 \pm 4.62 \\
85(82-89)\end{array}$ & $<0.001$ \\
\hline Female $(n, \%)$ & 6410 (59.1\%) & $20,801(57.98 \%)$ & $9745(60.36 \%)$ & $36,956(58.8 \%)$ & $<0.001$ \\
\hline \multicolumn{6}{|l|}{ Hospital length of stay (days) } \\
\hline $\begin{array}{l}\text { Mean } \pm \text { SD } \\
\text { Median (IQR) }\end{array}$ & $\begin{array}{l}6.77 \pm 8.35 \\
4(2-8)\end{array}$ & $\begin{array}{l}6.09 \pm 7.93 \\
3(5-7)\end{array}$ & $\begin{array}{l}8.25 \pm 9.16 \\
5(3-10)\end{array}$ & $\begin{array}{l}6.76 \pm 8.38 \\
5(3-8)\end{array}$ & $<0.001$ \\
\hline ICU admission rate & $247(2.28 \%)$ & $8079(22.52 \%)$ & $417(2.6 \%)$ & $8743(13.9 \%)$ & $<0.001$ \\
\hline \multicolumn{6}{|l|}{ ICU length of stay (days) } \\
\hline $\begin{array}{l}\text { Mean } \pm \text { SD } \\
\text { Median (IQR) }\end{array}$ & $\begin{array}{l}3.79 \pm 5.94 \\
2(1-4)\end{array}$ & $\begin{array}{l}3.48 \pm 5.04 \\
2.05(1.15-3.87)\end{array}$ & $\begin{array}{l}3.92 \pm 10.51 \\
2(1-4)\end{array}$ & $\begin{array}{l}3.49 \pm 5.07 \\
2.04(1.14-3.88)\end{array}$ & 0.34 \\
\hline \multicolumn{6}{|l|}{ LAPS score } \\
\hline $\begin{array}{l}\text { Mean } \pm \text { SD } \\
\text { Median (IQR) }\end{array}$ & $\begin{array}{l}28.98 \pm 22.74 \\
24(11-42)\end{array}$ & $\begin{array}{l}27.53 \pm 19.81 \\
24(13-37)\end{array}$ & $\begin{array}{l}22.51 \pm 16.08 \\
20(11-31)\end{array}$ & $\begin{array}{l}26.49 \pm 19.63 \\
23(12-36)\end{array}$ & $<0.001$ \\
\hline \multicolumn{6}{|l|}{ In-hospital death $(n, \%)$} \\
\hline $\begin{array}{l}\text { Ward } \\
\text { ICU } \\
\text { Total }\end{array}$ & $\begin{array}{l}725(6.84 \%) \\
99(40.08 \%) \\
824(7.6 \%)\end{array}$ & $\begin{array}{l}261(0.94 \%) \\
1120(13.86 \%) \\
1381(3.85 \%)\end{array}$ & $\begin{array}{l}689(4.38 \%) \\
86(20.62 \%) \\
775(4.8 \%)\end{array}$ & $\begin{array}{l}1675(3.09 \%) \\
1305(14.93 \%) \\
2980(4.74 \%)\end{array}$ & $<0.001$ \\
\hline Discharged home & 9931 (91.6\%) & $15,408(42.9 \%)$ & $8388(52.0 \%)$ & $33,727(53.65 \%)$ & $<0.001$ \\
\hline \multicolumn{6}{|l|}{ Charlson comorbidity index } \\
\hline $\begin{array}{l}\text { Mean } \pm \text { SD } \\
\text { Median (IQR) }\end{array}$ & $\begin{array}{l}5.37 \pm 1.48 \\
5(4-6)\end{array}$ & $\begin{array}{l}6.46 \pm 2.24 \\
6(5-8)\end{array}$ & $\begin{array}{l}4.93 \pm 1.62 \\
4(4-5)\end{array}$ & $\begin{array}{l}5.88 \pm 2.09 \\
5(4-7)\end{array}$ & $<0.001$ \\
\hline $\begin{array}{l}\text { Patients readmitted in any depart- } \\
\text { ment }(n, \%)\end{array}$ & $3085(28.4 \%)$ & $13,338(37.2 \%)$ & $4934(30.6 \%)$ & $21,357(34.0 \%)$ & $<0.001$ \\
\hline $\begin{array}{l}\text { Days to first readmission in any } \\
\text { department (median, IQR) }\end{array}$ & $36(12-85)$ & $31(10-75)$ & $30(4-85)$ & $31(9-78.5)$ & $<0.001$ \\
\hline \multicolumn{6}{|l|}{ Primary diagnosis $(n, \%)$} \\
\hline Abdominal pain & $180(1.66 \%)$ & $155(0.43 \%)$ & $106(0.66 \%)$ & $441(0.7 \%)$ & $<0.001$ \\
\hline Cholecystitis/cholangitis & $109(1 \%)$ & $246(0.69 \%)$ & $57(0.35 \%)$ & $412(0.7 \%)$ & $<0.001$ \\
\hline Acute kidney injury & $107(0.99 \%)$ & $830(2.31 \%)$ & $167(1.03 \%)$ & $1104(1.8 \%)$ & $<0.001$ \\
\hline Acute pancreatitis & $69(0.64 \%)$ & $161(0.45 \%)$ & $92(0.57 \%)$ & $322(0.5 \%)$ & 0.03 \\
\hline Acute respiratory failure & $110(1.01 \%)$ & $218(0.61 \%)$ & $41(0.25 \%)$ & $369(0.6 \%)$ & $<0.001$ \\
\hline URTI & $69(0.64 \%)$ & $53(0.15 \%)$ & $26(0.16 \%)$ & $148(0.2 \%)$ & $<0.001$ \\
\hline DVT PE & $79(0.73 \%)$ & $329(0.92 \%)$ & $81(0.5 \%)$ & $489(0.8 \%)$ & $<0.001$ \\
\hline Anemia & $142(1.31 \%)$ & $50(0.14 \%)$ & $119(0.74 \%)$ & $311(0.5 \%)$ & $<0.001$ \\
\hline Atrial fibrillation/flutter & $247(2.28 \%)$ & 705 (1.97\%) & $288(1.78 \%)$ & $1240(2.0 \%)$ & 0.02 \\
\hline Cellulitis & $105(0.97 \%)$ & $429(1.2 \%)$ & $190(1.18 \%)$ & $724(1.2 \%)$ & 0.14 \\
\hline Stroke and TIA & $438(4.04 \%)$ & $909(2.53 \%)$ & $669(4.14 \%)$ & $2016(3.2 \%)$ & $<0.001$ \\
\hline Heart failure & $257(2.37 \%)$ & $2222(6.19 \%)$ & $588(3.64 \%)$ & 3067 (4.9\%) & $<0.001$ \\
\hline Dizziness & $85(0.78 \%)$ & $77(0.21 \%)$ & 70 (0.43\%) & $232(0.4 \%)$ & $<0.001$ \\
\hline Fever & $589(5.43 \%)$ & $89(0.25 \%)$ & $20(0.12 \%)$ & $698(1.1 \%)$ & $<0.001$ \\
\hline Femoral fracture & $564(5.2 \%)$ & $1030(2.87 \%)$ & $1485(9.2 \%)$ & 3079 (4.9\%) & $<0.001$ \\
\hline Hyponatremia & $110(1.01 \%)$ & $171(0.48 \%)$ & $62(0.38 \%)$ & $343(0.5 \%)$ & $<0.001$ \\
\hline COPD & $144(1.33 \%)$ & $277(0.77 \%)$ & $375(2.3 \%)$ & $796(1.3 \%)$ & $<0.001$ \\
\hline Dyspnea & 505 (4.66\%) & $104(0.29 \%)$ & $30(0.19 \%)$ & $639(1.0 \%)$ & $<0.001$ \\
\hline Pneumonia & $610(5.62 \%)$ & $1208(3.37 \%)$ & $680(4.21 \%)$ & $2498(4.0 \%)$ & $<0.001$ \\
\hline Syncope & $304(2.8 \%)$ & $421(1.17 \%)$ & $245(1.52 \%)$ & $970(1.5 \%)$ & $<0.001$ \\
\hline Sepsis & 411 (3.79\%) & $1433(3.99 \%)$ & $169(1.05 \%)$ & $2013(3.2 \%)$ & $<0.001$ \\
\hline Urinary tract infection & 505 (4.66\%) & $1026(2.86 \%)$ & $410(2.54 \%)$ & $1941(3.1 \%)$ & $<0.001$ \\
\hline
\end{tabular}

Bold value indicates significance $p$ value $<0.05$

LAPS laboratory-based Acute Physiology Score, ICU intensive care unit, URT/ upper respiratory tract infection, DVTPE deep vein thrombosis and pulmonary embolism, TIA transient ischemic attack, COPD chronic obstructive pulmonary disease 
highest probability of ICU admissions are described in Additional file 1: Table S1.

\section{Characteristics of ICU admission}

The variables associated with higher probability of ICU admission in the American cohort were: younger age, male sex, higher LAPS scores, lower Charlson comorbidity index score, and the four following primary diagnoses-acute respiratory failure, sepsis, stroke or transient ischemic attack, and deep vein thrombosis or pulmonary embolism (Table 2). Detailed characteristics of patient admitted to the ICU compared to those who were not admitted are described in Additional file 1: Table S2. In the model predicting ICU admission probability, patients in the 5 th quintile had a probability of $43-100 \%$ to be admitted to an ICU in USA. Characteristics of patients from the 5th quintile are described in Additional file 1: Tables S1 and S3. The actual ICU allocation of the patients in the fifth quintile was $67.6 \%$ in USA, $22.1 \%$ in Australia, and $6.0 \%$ in Israel (Table 3 ).

\section{In-hospital and long-term mortality}

In-hospital death rates were $7.6 \%, 4.8 \%$, and $3.9 \%$ in Israel, Australia, and USA, respectively (Table 1). In the 5 th quintile of the patients with the highest probability to be admitted to USA ICU, in-hospital death rates were $22.1 \%$ in Boston, $29.8 \%$ in Australia, and $52.3 \%$ in Israel (Table 3). The median initial Sequential Organ Failure Assessment (SOFA) score for patients admitted to the ICU in BIDMC was 4, compared to 8 in the Israeli ICU (Additional file 1: Table S2). The mortality rates of patients admitted to the ICU were $13.9 \%$ and $40.1 \%$ in USA and Israel, respectively, resulting in a standardized mortality ratio (SMR) of 0.69 and 1.2, according to the predicted mortality based on SOFA scores [17].

Figure 1 and Additional file 1: Table S5 show mortality data of patients with the highest probability of ICU admissions in the Israeli and Australian cohorts, compared to the MIMIC-III cohort of BIDMC. After 6 and 12 months the survival rates were $62 \%$ and $58 \%, 74 \%$ and $66 \%$, and $69 \%$ and $60 \%$ in USA, Australia, and Israel, respectively ( $p$ value $<0.001$ for both periods, log-rank test). At 24 months, the survival rates in the USA and Australia were $53 \%$, while in Israel $48 \%$ ( $p$ value 0.06 ).

\section{Discussion}

To the best of our knowledge, this is the first comparison of in-hospital and short- and long-term mortality of older adults ( $\geq 80$ years) from three different developed countries across three continents. We found that older adults at a medical center with high ICU capacity (USA) were admitted to the ICU ten times more than in Israel and Australia, which have much lower ICU capacities.
Table 2 Multivariable logistic regression model for ICU admission in the American cohort ${ }^{a}$

\begin{tabular}{|c|c|c|c|}
\hline Variable & Odds ratio $(95 \% \mathrm{Cl})$ & $P$ value & Coefficient \\
\hline Female & $0.94(0.89-0.99)$ & 0.046 & -0.059 \\
\hline \multicolumn{4}{|l|}{ Age } \\
\hline $\begin{array}{l}90 \text { and above } \\
86-89 \\
83-85 \\
80-82\end{array}$ & $\begin{array}{l}0.82(0.75-0.89) \\
0.85(0.79-0.92) \\
0.96(0.88-1.04) \\
1\end{array}$ & $\begin{array}{l}<0.001 \\
<0.001 \\
0.27 \\
\text { Reference }\end{array}$ & $\begin{array}{l}-0.202 \\
-0.161 \\
-0.044 \\
\text { Reference }\end{array}$ \\
\hline \multicolumn{4}{|l|}{ LAPS score } \\
\hline $\begin{array}{l}38 \text { and higher } \\
24-37 \\
15-23 \\
6-14 \\
0-5\end{array}$ & $\begin{array}{l}14.65(12.88-16.65) \\
3.43(3.01-3.91) \\
2.03(1.77-2.32) \\
1.35(1.16-1.58) \\
1\end{array}$ & $\begin{array}{l}<0.001 \\
<0.001 \\
<0.001 \\
<0.001 \\
\text { Reference }\end{array}$ & $\begin{array}{l}2.684 \\
1.234 \\
0.707 \\
0.304 \\
\text { Reference }\end{array}$ \\
\hline \multicolumn{4}{|l|}{$\begin{array}{l}\text { Charlson comorbidity } \\
\text { index }\end{array}$} \\
\hline $\begin{array}{l}7 \text { and higher } \\
6 \\
0-5\end{array}$ & $\begin{array}{l}0.92(0.85-1.002) \\
0.86(0.8-0.92) \\
1\end{array}$ & $\begin{array}{l}0.05 \\
<0.001 \\
\text { Reference }\end{array}$ & $\begin{array}{l}0.079- \\
-0.151 \\
\text { Reference }\end{array}$ \\
\hline \multicolumn{4}{|l|}{ Primary diagnosis ${ }^{b}$} \\
\hline $\begin{array}{l}\text { Acute respiratory } \\
\text { failure }\end{array}$ & $21.61(12.53-37.25)$ & $<0.001$ & 3.073 \\
\hline Sepsis & $4.87(4.27-5.55)$ & $<0.001$ & 1.583 \\
\hline Stroke and TIA & $2.25(1.91-2.64)$ & $<0.001$ & 0.81 \\
\hline DVTPE & $1.45(1.11-1.91)$ & 0.01 & 0.374 \\
\hline Acute pancreatitis & $0.88(0.59-1.32)$ & 0.55 & -0.123 \\
\hline Pneumonia & $0.85(0.73-0.99)$ & 0.03 & -0.165 \\
\hline $\begin{array}{l}\text { Cholecystitis/chol- } \\
\text { angitis }\end{array}$ & $0.81(0.6-1.11)$ & 0.2 & -0.205 \\
\hline $\begin{array}{l}\text { Atrial fibrillation/ } \\
\text { flutter }\end{array}$ & $0.73(0.58-0.92)$ & 0.01 & -0.313 \\
\hline Heart failure & $0.72(0.64-0.81)$ & $<0.001$ & -0.332 \\
\hline Femoral fracture & $0.55(0.45-0.66)$ & $<0.001$ & -0.602 \\
\hline Dyspnea & $0.21(0.08-0.53)$ & $<0.001$ & -1.557 \\
\hline Fever & $0.17(0.06-0.47)$ & $<0.001$ & -1.779 \\
\hline UTI & $0.17(0.13-0.23)$ & $<0.001$ & -1.756 \\
\hline Syncope & $0.09(0.04-0.18)$ & $<0.001$ & -2.403 \\
\hline
\end{tabular}

LAPS laboratory-based Acute Physiology Score, ICU intensive care unit, URTI upper respiratory tract infection, DVTPE deep vein thrombosis and pulmonary embolism, TIA transient ischemic attack, COPD chronic obstructive pulmonary disease, UT/ urinary tract infection

${ }^{a}$ The model has $\mathrm{c}$-statistic of 0.8 , demonstrating good discrimination

${ }^{b}$ Diagnoses that were included in the model but do not appear in the table: abdominal pain, URTI, anemia, cellulitis, dizziness, hyponatremia, COPD

In-hospital deaths were negatively associated with ICU admission rate, lowest in the USA and highest in Israel.

The predicted in-hospital mortality for LAPS scores of $20-29$ is 3\% [15]. The mean LAPS score in our entire cohort was 26 and the overall mortality was $4.7 \%$, higher than predicted by the LAPS score, with significant differences between the countries as described in Table 1 . The higher-than-expected mortality rate was observed also in the ICUs, where the mean LAPS score was 43.9 
Table 3 Admission allocation (ICU vs. general ward) and in-hospital mortality rates according to different quintiles in every country

\begin{tabular}{|c|c|c|c|c|c|c|c|c|}
\hline $\begin{array}{l}\text { Country/quintile } \\
\text { (predicted } \\
\text { probability) }\end{array}$ & Admission alloca & ion & $1(0-4 \%)$ & $2(5-8 \%)$ & $3(9-16 \%)$ & $4(17-42 \%)$ & $5(43-100 \%)$ & Total \\
\hline \multirow{5}{*}{$\begin{array}{l}\text { United States, n } \\
\text { (\% of predicted } \\
\text { probability) }\end{array}$} & \multirow{2}{*}{$\begin{array}{l}\text { Ward (\% of entire } \\
\text { quintile) }\end{array}$} & Actual Admission & $2734(97.61 \%)$ & $5653(92.29 \%)$ & $9923(88.39 \%)$ & $7811(73.97 \%)$ & $1675(32.44 \%)$ & 27,796 \\
\hline & & In-hospital death & $5(0.18 \%)$ & $15(0.27 \%)$ & $51(0.51 \%)$ & $5 \%)$ & $92(5.49 \%)$ & 261 \\
\hline & \multirow{2}{*}{$\begin{array}{l}\text { ICU (\% of entire } \\
\text { quintile) }\end{array}$} & Actual Admission & $67(2.39 \%)$ & $472(7.71 \%)$ & $1303(11.61 \%)$ & $2749(26.03 \%)$ & $3488(67.56 \%)$ & 8079 \\
\hline & & & $0(0 \%)$ & & $70(5.37 \%)$ & $264(9.6 \%)$ & $770(22.08 \%)$ & 1120 \\
\hline & \multicolumn{2}{|c|}{ Total (\% of entire cohort) } & $2801(7.81 \%)$ & $6125(17.07 \%)$ & $11,226(31.29 \%)$ & $10,560(29.44 \%)$ & $5163(14.39 \%)$ & 35,875 \\
\hline \multirow{5}{*}{$\begin{array}{l}\text { Australia, n (\% of } \\
\text { predicted prob- } \\
\text { ability) }\end{array}$} & \multirow{2}{*}{$\begin{array}{l}\text { Ward (\% of entire } \\
\text { quintile) }\end{array}$} & Actual Admission & $1473(99.33 \%)$ & $3079(98.88 \%)$ & $5507(98.41 \%)$ & $4700(97.41 \%)$ & 968 (85.97\%) & 15,727 \\
\hline & & In-hospital death & $20(1.36 \%)$ & $64(2.08 \%)$ & $172(3.12 \%)$ & $294(6.26 \%)$ & $139(14.36 \%)$ & 689 \\
\hline & \multirow{2}{*}{$\begin{array}{l}\text { ICU (\% of entire } \\
\text { quintile) }\end{array}$} & Actual Admission & $10(0.67 \%)$ & $35(1.12 \%)$ & $89(1.59 \%)$ & $125(2.59 \%)$ & $158(14.03 \%)$ & 417 \\
\hline & & In-hospital death & $0(0 \%)$ & $6(17.14 \%)$ & $13(14.61 \%)$ & $20(16 \%)$ & $47(29.75 \%)$ & 86 \\
\hline & \multicolumn{2}{|c|}{ Total (\% of entire cohort) } & $1483(9.19 \%)$ & $3114(19.29 \%)$ & $5596(34.66 \%)$ & 4825 (29.89\%) & $1126(6.97 \%)$ & 16,144 \\
\hline \multirow{5}{*}{$\begin{array}{l}\text { Israel, n (\% of } \\
\text { predicted prob- } \\
\text { ability) }\end{array}$} & \multirow{2}{*}{$\begin{array}{l}\text { Ward (\% of entire } \\
\text { quintile) }\end{array}$} & Actual admission & $1682(99.47 \%)$ & $1897(99.11 \%)$ & 2715 (98.8\%) & $2559(97.08 \%)$ & $1747(94.03 \%)$ & 10,600 \\
\hline & & In-hospital death & $24(1.43 \%)$ & $24(1.27 \%)$ & $57(2.1 \%)$ & $147(5.74 \%)$ & $473(27.07 \%)$ & 725 \\
\hline & \multirow{2}{*}{$\begin{array}{l}\text { ICU (\% of entire } \\
\text { quintile) }\end{array}$} & Actual admission & $9(0.53 \%)$ & $17(0.89 \%)$ & $33(1.2 \%)$ & 77 (2.92\%) & $111(5.97 \%)$ & 247 \\
\hline & & In-hospital death & $2(22.22 \%)$ & $4(23.53 \%)$ & $10(30.3 \%)$ & $25(32.47 \%)$ & $58(52.25 \%)$ & 99 \\
\hline & \multicolumn{2}{|c|}{ Total (\% of entire cohort) } & $1691(15.59 \%)$ & $1914(17.65 \%)$ & $2748(25.33 \%)$ & $2636(24.3 \%)$ & $1858(17.13 \%)$ & 10,847 \\
\hline \multicolumn{3}{|c|}{$p$ value (difference between countries in ICU admissions) } & $<0.001$ & $<0.001$ & $<0.001$ & $<0.001$ & $<0.001$ & $<0.00$ \\
\hline
\end{tabular}

Quintiles represent predicted probabilities for admission in an intensive care unit according to the American cohort (see Table 2)

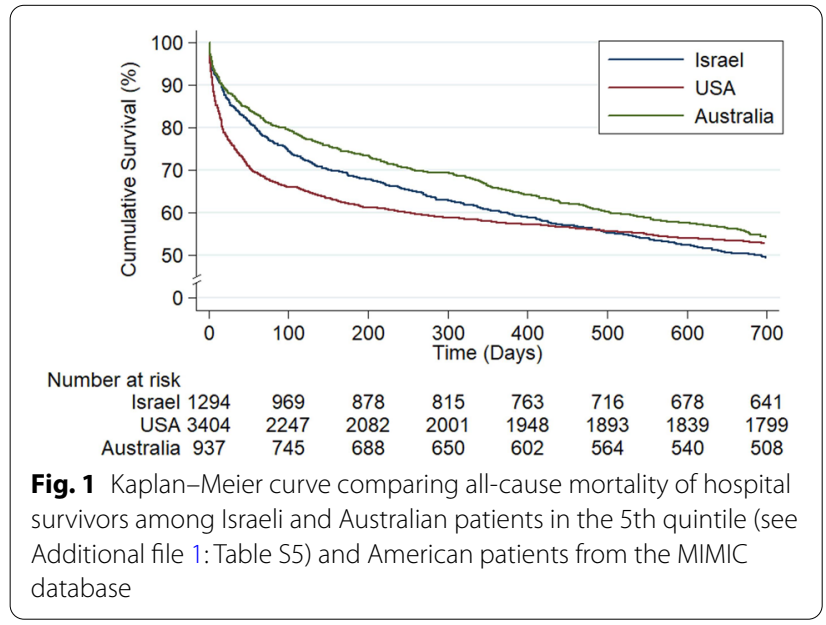

(predicted in-hospital mortality is $\sim 7 \%$ ) and the overall mortality was $14.9 \%$. This difference between the observed and expected mortality can be explained by the difference between our study population and the population which was used to create the LAPS score. The LAPS score was created from a general population that included also younger patients with less comorbidities, as opposed to our population, and the score does not consider comorbidities at all, only laboratory results at admission. When considering only in-ICU mortality, the difference between the initial SOFA scores of Israel and USA reflects the difference in the severity of the patients and thus the difference in the mortality data. In contrast to its lowest in-hospital mortality rate, the 1-year mortality rate was highest in the American cohort when comparing patients admitted to ICUs at USA with Israeli and Australian patients that had the highest probability for ICU admission. The time to readmission was shorter in the American and Australian cohorts. This supports the hypothesis that although ICU admission reduces inhospital mortality it does not significantly improve longterm outcomes such as readmissions and mortality. This finding is consistent with another previous study [18]. Another contributing factor for this finding is the higher Charlson scores in the American cohort compared to the other two which increases the likelihood of mortality and shortens readmission times. A large randomized controlled trial showed that a program to promote ICU admission of older adults significantly increased ICU admissions, but did not reduce 6 months mortality [19]. On the contrary, a large international study concluded that although older adults have more intensive care unit refusals than younger patients and suffer from higher mortality rates when admitted to an ICU, their actual survival benefit when they enter the ICU is greater than younger patients [12]. Whereas readmissions to the hospital occurred in about a third of the cases in 
all countries, readmission of patients hospitalized in the ICU on their index admission and then again in the ICU within 6 months were rare in Israel and much more common in Australia and in the USA (Additional file 1: Table S2). This also reflects the different ICU admission policies between the hospitals.

The rates of patients that were discharged home were also significantly different between the countries. This shows that increasing ICU beds capacity, which is expected to lead to increased survival rates, must be accompanied by appropriate long-term facilities that can handle the increasing numbers of older adults surviving hospital admissions. The rates of patients discharged home in the American and Australian cohorts was similar to other American and German cohorts [20,21].

Long-term mortality may be affected by the underlying health of the population in that country. However, for these three countries, the life expectancy at age 80 is very similar (in Australia 9.87 years, in USA 9.6, and in Israel 9.66 years) $[22,23]$.

For patients with advanced malignancy, therapies that prolong life expectancy in weeks or months are considered substantial and many resources are invested in them [24]. It cannot be justified to withhold ICU admission for all patients above a certain age. At times of scarcity, however, it may be justified to prioritize the younger patients, in order to maximize the benefits for the largest number of people [25].

Augmentation of ICU capacity may allow admission of older adults and in-hospital mortality benefits may accrue. However, there is still the question of whether the addition of beds always means that more lives will be saved or whether there is a point at which no additional mortality benefit will be gained. With an abundance of ICU beds may come the possibility of increasing harm in the forms of unnecessary costs, poor quality of deaths (i.e., excessively intensive), poor quality of life after ICU discharge, and iatrogenic complications [26]. The identification of those very old, who survived a long time after an ICU admission, with an acceptable quality of life, compared to those that did not should be the focus of future research. The ethical question: how much money, personnel, ICU beds, and ICU units should we invest to save a life, even in the short term, is a relevant question for ethicists, health care personnel, health care administrators, and society. The answer to these questions might also vary substantially between the countries in our study and between other developed countries with distinct socio-cultural beliefs. This is a question not too far away from challenging us as in years to come the proportion of older adults continues to increase.
Our study has some limitations. We did not assess frailty and quality of life to any of our patients admitted to the hospital or who survived the ICU admission. Being discharged alive from the ICU is not necessarily the main preference of our patients and families [27]. We believe that the assessment of functional status, well-being, and quality of life in this population should be the focus of future studies. We did not assess any of the costs related to ICU admissions, ward admissions, long-term facilities on health care, medical centers, community, and families. Differences identified between the countries may reflect the population underlying characteristics, either in terms of health, different outpatient care structure, different age composition of the population, life expectancy, or post-hospitalization care. Measurable characteristics are similar for the different populations, but unmeasured confounders cannot entirely be ruled out. Our data are not able to provide a reason for the large difference in number of patients between the countries despite similar number of hospital beds overall. In addition, only one hospital represents each country in the study and none of the studied hospitals can be a representative of the entire country. Nevertheless, it should be emphasized that the main comparison is the ICU bed saturation (ICU beds to hospital beds ratio), which is similar in other hospitals within each country. The long-term mortality was not available to us from the American cohort. Only in-hospital mortality was documented. We used MIMIC III data, extracted from the same hospital (BIDMC), age, ICUs, and included some years of study. We believe that these data reflect accurately the long-term survival of the older adults from our American cohort.

\section{Conclusions}

Comparing three large academic medical centers from three different countries and continents, higher ICU bed capacity and more liberal ICU admission policies are associated with higher in-hospital survival of older adults, but long-term survival (6-24 months) is similar, and number of readmissions is higher. The strategies for allocation of ICU beds for older adults remain an area of further research.

\section{Abbreviations}

ICU: Intensive care unit; SUMC: Soroka University Medical Center; SCGH: Sir Charles Gairdner Hospital; BIDMC: Beth Israel Deaconess Medical Center; USA: United States of America; CMO: Comfort measures only; LAPS: Laboratory-Based Acute Physiology Score; MIMIC-III: Medical information mart for intensive care-III. 


\section{Supplementary Information}

The online version contains supplementary material available at https://doi. org/10.1186/s13613-022-00994-x.

Additional file 1: Table S1. Characteristics of the 5th quintile from Table 3. Table S2. Characteristics of The Patients at First Admission, Comparing ICU Admitted Patients to Ward Admitted Patients. Table S3. Characteristics of the patients admitted to the ICU in the 5th quintile from Table S1. Table S4. Characteristics of the patients not admitted to the ICU in the 5 th quintile from. Table S5. Kaplan-Meier mean estimates for 4 time points.

\section{Acknowledgements}

The authors wish to thank the staff at the Western Australian Data Linkage Branch (datasets Hospital Morbidity and Mortality Data) and Pathwest Western Australia.

\section{Authors' contributions}

Conceptualization: LF, VN; methodology: VN, LF, RA; formal analysis and investigation: RA; writing —original draft preparation: RA, LF, MA, SB; writing —review and editing: All authors; supervision: DT, VN, LF. All authors read and approved the final manuscript.

\section{Funding}

No funding sources were used in the study.

\section{Availability of data and materials}

The data used in the analysis of this study are not publicly available due to the requirements of the IRB Committee, can be considered by the IRB committee and data custodians through request via the corresponding author.

\section{Declarations}

\section{Ethics approval and consent to participate}

The study was performed in accordance with the ethical standards as laid down in the 1964 Declaration of Helsinki and its later amendments. The study was approved by the institutional review board of all medical centersSUMC (confirmation number 0423-16), SCGH and WA Department of Health (confirmation number 2015-04) and BIDMC (confirmation number 2012-P$000120 / 4)$. The IRB approvals exempted the study from informed consent due to the retrospective data collection that maintained subject confidentiality. Patient records were anonymized and de-identified prior to analysis.

\section{Consent for publication}

Not applicable.

\section{Competing interests}

The authors declare that they have no competing interests.

\section{Author details}

${ }^{1}$ Clinical Research Center, Soroka University Medical Center, Beer Sheva, Israel. ${ }^{2}$ Faculty of Health Sciences, Ben-Gurion University of the Negev, Beer Sheva, Israel. ${ }^{3}$ Sir Charles Gairdner Hospital, Perth, Australia. ${ }^{4}$ School of Public Health, Curtin University, Perth, Australia. ${ }^{5}$ School of Medicine, University of Western Australia, Perth, Australia. ${ }^{6}$ Department of Anesthesia, Critical Care and Pain Medicine, Harvard Medical School, Beth Israel Deaconess Medical Center, Boston, MA, USA. ${ }^{7}$ Center for Anesthesia Research Excellence (CARE), Department of Anesthesia, Critical Care and Pain Medicine, Beth Israel Deaconess Medical Center, Boston, MA, USA. ${ }^{8}$ Medical Intensive Care Unit, Faculty of Health Sciences, Soroka University Medical Center, Ben-Gurion University of the Negev, Beer Sheva, Israel.

Received: 9 November 2021 Accepted: 7 February 2022

Published online: 04 March 2022

\section{References}

1. SM Bagshaw SAR Webb A Delaney C George D Pilcher GK Hart 2009 Very old patients admitted to intensive care in Australia and New Zealand: a multi-centre cohort analysis Crit Care BioMed Central. 13 R45

2. N Lerolle L Trinquart C Bornstain JM Tadié A Imbert JL Diehl 2010 Increased intensity of treatment and decreased mortality in elderly patients in an intensive care unit over a decade Crit Care Med 385964

3. United Nations D of E and SA. World Population Ageing 2019 [Internet]. 2019 [cited 2021 May 6]. Available from: https://www.un.org/en/devel opment/desa/population/publications/pdf/ageing/WorldPopulation Ageing2019-Highlights.pdf.

4. NA Halpern SM Pastores RJ Greenstein 2004 Critical care medicine in the United States 1985-2000: an analysis of bed numbers, use, and costs Crit Care Med Crit Care Med 3212541259

5. DM Berwick AD Hackbarth 2012 Eliminating waste in US health care JAMA J Am Med Assoc 30715131516

6. L Fuchs CE Chronaki S Park V Novack Y Baumfeld D Scott 2012 ICU admission characteristics and mortality rates among elderly and very elderly patients Intensive Care Med 3816541661

7. CL Sprung M Baras G lapichino J Kesecioglu A Lippert C Hargreaves 2012 The Eldicus prospective, observational study of triage decision making in European intensive care units: Part I-European Intensive Care Admission Triage Scores Crit Care Med 40125131

8. M Garrouste-Orgeas A Boumendil D Pateron P Aergerter D Somme T Simon 2009 Selection of intensive care unit admission criteria for patients aged 80 years and over and compliance of emergency and intensive care unit physicians with the selected criteria: an observational, multicenter, prospective study Crit Care Med 3729192928

9. E Simchen CL Sprung N Galai Y Zitser-Gurevich Y Bar-Lavi G Gurman 2004 Survival of critically ill patients hospitalized in and out of intensive care units under paucity of intensive care unit beds Crit Care Med Crit Care Med 3216541661

10. R Robert J Reignier C Tournoux-Facon T Boulain O Lesieur V Gissot 2012 Refusal of intensive care unit admission due to a full unit: impact on mortality Am J Respir Crit Care Med 18510811087

11. A Roch S Wiramus V Pauly JM Forel C Guervilly M Gainnier 2011 Longterm outcome in medical patients aged 80 or over following admission to an intensive care unit Crit Care 15 R36

12. CL Sprung A Artigas J Kesecioglu A Pezzi J Wiis R Pirracchio 2012 The Eldicus prospective, observational study of triage decision making in European intensive care units. Part II: Intensive care benefit for the elderly Crit Care Med 40132138

13. HWunsch DC Angus DA Harrison WT Linde-Zwirble KM Rowan 2011 Comparison of medical admissions to intensive care units in the United States and United Kingdom Am J Respir Crit Care Med 18316661673

14. H Quan B Li CM Couris K Fushimi P Graham P Hider 2011 Updating and validating the Charlson comorbidity index and score for risk adjustment in hospital discharge abstracts using data from 6 countries Am J Epidemiol 173676682

15. GJ Escobar JD Greene P Scheirer MN Gardner D Draper P Kipnis 2008 Risk-adjusting hospital inpatient mortality using automated inpatient, outpatient, and laboratory databases Med Care 46232239

16. Johnson AEW, Pollard TJ, Shen L, Lehman LWH, Feng M, Ghassemi M, et al. MIMIC-III, a freely accessible critical care database. Sci Data. 2016;3.

17. F Lopes Ferreira D Peres Bota A Bross C Mélot JL Vincent 2001 Serial evaluation of the SOFA score to predict outcome in critically ill patients J Am Med Assoc 28617541758

18. L Fuchs V Novack S McLennan L Anthony Celi Y Baumfeld S Park 2014 Trends in severity of illness on ICU admission and mortality among the elderly PLoS One Public Lib Sci 9 e93234 e93234

19. B Guidet G Leblanc T Simon M Woimant JP Quenot O Ganansia 2017 Effect of systematic intensive care unit triage on long-term mortality among critically ill elderly patients in France a randomized clinical trial JAMA J Am Med Assoc 31814501459

20. VK Moitra C Guerra WT Linde-Zwirble H Wunsch 2016 Relationship between ICU length of stay and long-term mortality for elderly ICU survivors Crit Care Med 44655662 
21. S Becker J Müller G Heer de S Braune V Fuhrmann S Kluge 2015 Clinical characteristics and outcome of very elderly patients $\geq 90$ years in intensive care: a retrospective observational study Ann Intensive Care 518

22. International health data comparisons, 2020, Life expectancy, mortality and causes of death - Australian Institute of Health and Welfare [Internet]. [cited 2021 May 6]. Available from: https://www.aihw.gov.au/reports/ international-comparisons/international-health-data-comparisons-2018/ contents/life-expectancy-mortality-and-causes-of-death.

23. Knoema. Life expectancy at age 80 years for both sexes combined [Internet]. 2020 [cited 2021 May 6]. Available from: https://knoema.com/atlas/ topics/Demographics/Age/Life-expectancy-at-age-80-years.

24. JD Wolchok V Chiarion-Sileni R Gonzalez P Rutkowski J-J Grob CL Cowey 2017 Overall survival with combined nivolumab and ipilimumab in advanced melanoma N Engl J Med (NEJM/MMS) 37713451356

25. Haas LEM, de Lange DW, van Dijk D, van Delden JJM. Should we deny ICU admission to the elderly? Ethical considerations in times of COVID-19. Crit Care. 2020.

26. Wunsch $\mathrm{H}$. Is there a starling curve for intensive care? Chest. 2012: 1393-9.

27. H Flaatten DW Lange De A Morandi FH Andersen A Artigas G Bertolini 2017 The impact of frailty on ICU and 30-day mortality and the level of care in very elderly patients ( $\geq 80$ years) Intensive Care Med 431820 1828

\section{Publisher's Note}

Springer Nature remains neutral with regard to jurisdictional claims in published maps and institutional affiliations.

\section{Submit your manuscript to a SpringerOpen ${ }^{\circ}$ journal and benefit from:}

- Convenient online submission

- Rigorous peer review

- Open access: articles freely available online

- High visibility within the field

- Retaining the copyright to your article

Submit your next manuscript at $\gg$ springeropen.com 